\title{
The effects of carotenoid and food intake on caudal fin regeneration in male guppies
}

\author{
G. R. Kolluru, N. C. Ruiz, N. Del Cid, E. Dunlop \\ AND G. F. GRETHER \\ Department of Ecology and Evolutionary Biology, University of California, Los \\ Angeles, 621 Charles E. Young Drive South, Los Angeles, CA 90095-1606, U.S.A.
}

\begin{abstract}
The trade-offs involved in allocating carotenoid pigments and food to healing and regrowing damaged caudal fin tissue $v$. other functions were examined in guppies Poecilia reticulata, a species in which females prefer males that display larger amounts of carotenoids in their skin. The guppies were derived from four natural populations in Trinidad that differed in resource availability but not predation intensity. Carotenoids, food and site of origin did not affect either absolute or relative fin regrowth, which suggested that fin regeneration in guppies was not constrained by carotenoid availability. It is possible that carotenoid intake influences fin regeneration in the presence of natural stressors such as predators. There was a significant negative interaction between food level in the laboratory and resource availability in the field: males from low-resource-availability sites regrew more fin tissue when raised on the high food level, and males from high-resource-availability sites regrew more fin tissue when raised on the low food level. The direction of this interaction runs counter to theoretical expectations.
\end{abstract}

Key words: carotenoids; fin regeneration; food intake; geographic variation; guppy; Poecilia reticulata.

\section{INTRODUCTION}

Individuals battling disease or injury face a trade-off in the allocation of limited resources to immunity and tissue repair $v$. other fitness-enhancing activities such as attracting mates. In many species of fishes and birds, males produce elaborate carotenoid-based sexual ornaments (Olson \& Owens, 1998; Møller et al., 2000), and mounting evidence suggests that carotenoids aid immune system functions in these species (Blount et al., 2003a; McGraw \& Ardia, 2003; Grether et al., 2004). Because animals must obtain carotenoids from their diet (Goodwin, 1984), the availability of these pigments may be limiting (KodricBrown 1989; Hill 1991; Olson \& Owens 1998; Grether et al., 1999). Sick or injured males therefore face a compromise when allocating carotenoids to sexual displays $v$. health-related physiological functions (Lozano, 1994; Olson \& 
Owens 1998). In addition to carotenoid intake, food intake in general is also a limiting factor for tissue repair, because both immune system activation and the formation of new tissue are energetically costly and divert energy resources from other functions (Munger \& Karasov, 1989; Siva-Jothy \& Thompson, 2002).

The remarkable ability of teleosts to regenerate damaged fins (Turnbull et al., 1998; Akimenko et al., 2003) has been exploited by developmental biologists seeking to understand the mechanisms underlying tissue regeneration (Santos-Ruiz et al., 2002; Nechiporuk \& Keating, 2002; Akimenko et al., 2003; Poss et al., 2003). Fin damage such as that incurred during aggressive encounters (Turnbull et al., 1998) or via experimental removal of fin tissue (Santos-Ruiz et al., 2002) makes the fish vulnerable to opportunistic bacterial and fungal infections (Latremouille, 2003). Therefore, successful fin regrowth in the face of such infectious agents is expected to involve both immune system activation and tissue regeneration, both of which are expected to be limited by carotenoid and food intake. The genetic basis of fin regeneration has been well-studied, however, environmental factors also influence the process (Weis \& Weis, 1976; Johnson \& Denton, 1977; Bakshi \& Hiradhar, 1997; Zodrow \& Tanguay, 2003). The influence of carotenoids and chitin (Lellis \& Barrows, 2000), and ration level (Moutou et al., 1998), on the degree of fin erosion caused by disease and fighting have been studied, but as far as is known, the influence of diet on fin regeneration has not.

Male guppies Poecilia reticulata Peters exhibit carotenoid-based sexual colouration that is absent in females. In mate choice tests, female guppies show a preference for high-carotenoid males (Kodric-Brown, 1989; Grether, 2000; Karino \& Shinjo, 2004). The availability of carotenoids is limiting for male sexual colouration in some guppy populations (Grether et al., 1999), and carotenoids have beneficial effects on at least one aspect of the immune system strength of males (Grether et al., 2004).

The interacting effects of carotenoid and food intake on the regrowth of experimentally-reduced caudal fins in male guppies derived from four natural populations in Trinidad were examined. This study tested the hypothesis that there is a trade-off in the allocation of these resources to fin regeneration $v$. other functions, such that males who are raised on high resource (e.g. carotenoid and food) levels would exhibit faster rates of fin regrowth than males raised on low resource levels. The experimental design also provided a test for genetic divergence in fin regeneration rates between guppy populations exposed to different levels of resource availability in the field. Males from low resource sites were predicted to exhibit greater plasticity in response to resource intake, because these males are more likely to be able to respond to short-term changes in food availability (Kolluru \& Grether, 2005).

Previous work on the effects of carotenoid intake on immune system function in guppies suggests that carotenoids affect different immune system components in different ways (Grether et al., 2004; Kolluru et al., in press). Compared with males raised on a trace-carotenoid diet, males raised on a high-carotenoid diet mounted a stronger immune response to transplanted tissue (allografted scales; Grether et al., 2004). Carotenoid intake had a non-linear effect, however, on the resistance of male guppies to a monogenean parasite, Gyrodactylus turnbulli: 
males raised on an intermediate level of carotenoids showed greater resistance than males raised on the trace- and high-carotenoid diets (Kolluru et al., in press). A plausible explanation for the latter result is that carotenoids strengthen parasite resistance at low levels, but benefit the parasite more than the host (by reducing oxidative stress that would otherwise harm the parasite) at high levels (Hõrak et al., 2004, developed a similar argument involving carotenoids in great tits Parus major infected with blood parasites). This study examined the influence of the same three dietary carotenoid levels on the ability of male guppies to regenerate damaged fins.

\section{MATERIALS AND METHODS}

\section{STUDY POPULATIONS}

The main source of food and carotenoids for guppies in the wild is attached unicellular algae, the abundance of which is largely a function of forest canopy cover. Streams that receive more light have larger standing crops of algae, but not correspondingly higher densities of guppies, than streams that receive less light (Grether et al., 2001). In the high-resource streams, female and juvenile guppies grow faster and males mature at larger sizes than their counterparts in the low-resource streams (Grether et al., 2001; G.F. Grether \& G.R. Kolluru, unpubl. data).

Four sites in the Northern Range of Trinidad were chosen using the same criteria as in Grether et al. (2001): 1) intact primary or old secondary growth rainforest, 2) relatively homogeneous forest canopy cover within each site, 3) separated from sites differing in predator assemblage by multiple barriers to guppy dispersal, including two or more waterfalls and 4) no predatory fish except Rivulus hartii (Boulenger). One stream was chosen with relatively low canopy openness and another with relatively high canopy openness in each of two phylogenetically distinct river drainages. This sampling design helped to control for phylogenetic effects, to the extent that populations within one drainage are genetically closer to each other than populations in different drainages, as would be expected from the dispersal mode of these fish. Previous work has shown that in streams with lower canopy openness, guppies ingest algae at lower rates and males have less carotenoid pigments in their orange spots (Grether et al., 1999, 2001). The names, resource availability categories and GPS co-ordinates (Universal Transverse Mercator Grid, Zone 20) of the sites are as follows: Aqui River (high-resource; PS 939 887 ) and a small unnamed tributary of the Madamas River (low-resource; PS 950 880) in the upper Madamas drainage; Small Crayfish River (high-resource, PS 965 835) and Large Crayfish River (low-resource, PS 965 832) in the upper Quare drainage. The fish used in the experiment were first-generation $\left(\mathrm{G}_{1}\right)$ laboratory descendants of fish collected in 2000 from eight to 10 pools per site.

\section{FOOD LEVEL AND CAROTENOID DIET MANIPULATION}

The laboratory populations were housed at the University of California, Los Angeles, U.S.A., campus in a temperature-controlled $\left(24 \cdot 0^{\circ} \mathrm{C}\right.$, range $\pm 4 \cdot 5^{\circ} \mathrm{C}$ water temperature) room at a 12L : 12D photoperiod (mixed daylight spectrum fluorescent and incandescent light). To prevent the fish from eating algae the water was treated with 2-chloro-4, 6-bis(ethylamino)-s-triazine (Algae Destroyer, Aquarium Pharmaceuticals, Chalfont, PA, U.S.A.), and visible algae was removed regularly. Wild-caught females were individually housed in 81 tanks, fed a standard diet of commercial flake food (Tetramin and Tetra Spirulina; Tetra, Blacksburg, VA, U.S.A.) twice daily (once daily on weekends) and allowed to give birth. 
The experiment involved a total of $173 \mathrm{G}_{1}$ male offspring. The fish were randomly assigned at birth to either the low or high food level treatment, and to either the trace, low or high carotenoid diet treatment. Prior to sexing, the fish were housed in 81 tanks in mixed-sex broods at densities of one to six fish per tank. Each tank potentially contained offspring from multiple females, but offspring did not vary in age by $>14$ days. Fish were sexed under a dissecting microscope well before sexual maturity, at either 13-15 weeks of age (low food) or 10-12 weeks of age (high food), while sedated with ethyl 3-aminobenzoate methane sulphonic acid salt (MS-222). Black pigment spots near the gonopore (females), and skin iridescence or the beginnings of gonopodial development in the anal fin (males) were used to determine sex. After sexing, males were housed at densities of one to four males per tank, with one companion female to allow mating, but still with no more than 14 days difference between the youngest and oldest males in a tank.

At least 4 weeks prior to the start of the experiment, males were moved into the experimental (8 1) tanks, after each male's unique colour pattern was sketched to individually identify the males in each tank. Each tank contained two or three males and one companion female, with the exception of five (out of a total of 72) tanks, which contained only one male and one companion female, due to a shortage in the availability of males from one of the sites. There was a wide age range ( 29 to 122 weeks at the time of testing) among the males available for use in the experiment. To avoid accidental differences in age among treatment groups, the range of ages of the males in each experimental tank was maximized.

To simulate low and high food availability conditions experienced by guppies in the wild, males were raised on one of two food levels in the laboratory. The fish were fed twice daily (once daily on weekends) using a specially designed Plexiglass feeding device equipped with Plexiglass cartridges each with a hole of a different diameter, that admitted precise quantities (by volume) of finely ground flake food into each tank. To determine an appropriate food dose per newborn fish on the high food level, different amounts were tried and uneaten food looked for in the tanks 10-15 min after the feedings. The smallest amount that usually resulted in some uneaten food was selected as the basal feeding unit (i.e. the amount given twice daily to a single newborn fish on the high food level). In a pilot experiment, the food amounts were increased every 1-3 weeks as the fish aged and the tanks monitored for uneaten food 10-15 min after the feedings and also for food accumulation from one feeding to the next. Food increments were adjusted to keep the high food level slightly higher than what the fish were usually willing to consume. In the resulting feeding schedule, food amounts were increased by $19.7 \%$ per week, on average, over weeks $1-6,13 \cdot 25 \%$, on average, over weeks $7-12$, and $3 \cdot 35 \%$, on average, over weeks 13-20. The low food level was maintained at approximately one third of the high food level, subject to the constraints imposed by the feeding device (the device could only deliver multiples of the basal feeding unit). Because male guppies grow very little after reaching sexual maturity (Snelson, 1989), food levels were not increased after 20 weeks of age.

The carotenoid diets (trace, low and high) were designed to contain different concentrations of the carotenoid pigments found in the natural diets of guppies but otherwise were identical. The basal (trace-carotenoid) diet contained white fish meal $(46 \cdot 0 \%)$, wheat flour $(45.4 \%)$, fish gelatine $(1.5 \%)$, sucrose $(2 \cdot 1 \%)$, cornstarch $(1.9 \%)$, vegetable oil $(2 \cdot 0 \%)$ and a vitamin premix $(1 \cdot 0 \%)$ containing vitamin A palminate, which cannot be metabolized into carotenoids, but no carotenoids. The low- and high-carotenoid diets also contained synthetic carotenoid products obtained from Roche Vitamins (Parsippany, NJ, U.S.A.): lutein trade grade, TG (assayed lutein content: $5 \cdot 4 \%$ ) and $\beta$-carotene cold water soluble, CWS (assayed $\beta$-carotene content: $13 \cdot 0 \%$ ). By dry mass, $0.115 \mathrm{mg} \mathrm{g}^{-1}$ of lutein TG and $0.154 \mathrm{mg} \mathrm{g}^{-1}$ of $\beta$-carotene CWS were added to the low-carotenoid diet; $28.454 \mathrm{mg} \mathrm{g}^{-1}$ lutein TG and $38.020 \mathrm{mg} \mathrm{g}^{-1} \beta$-carotene CWS: $38.020 \mathrm{mg} \mathrm{g}^{-1}$ were added to the high-carotenoid diet. The recipes were adjusted to ensure that each of the three diets contained equal proportions of the non-carotenoid constituents of the Roche products (fish gelatine, sucrose and cornstarch). The diets were manufactured by Ocean Star International, Inc. (Snowville, UT, U.S.A.) in multiple batches and stored before use at $-80^{\circ} \mathrm{C}$. Based on high performance liquid 
chromatography (HPLC) analyses of diet samples, the carotenoid content of the tracecarotenoid diet was negligible $\left(\leq 0 \cdot 2 \mu \mathrm{g} \mathrm{g}^{-1}\right)$, the low-carotenoid diet contained $2 \cdot 85 \mu \mathrm{g} \mathrm{g}^{-1}$ lutein, $0.21 \mu \mathrm{g} \mathrm{g}^{-1}$ zeaxanthin, $1.99 \mu \mathrm{g} \mathrm{g}^{-1} \beta$-carotene $\left(5.05 \mu \mathrm{g} \mathrm{g}^{-1}\right.$ total carotenoids), and the high-carotenoid diet contained $745 \cdot 57 \mu \mathrm{g} \mathrm{g}^{-1}$ lutein, $71.43 \mu \mathrm{g} \mathrm{g}^{-1}$ zeaxanthin and $522 \cdot 30 \mu \mathrm{g} \mathrm{g}^{-1} \beta$-carotene $\left(1339 \cdot 30 \mu \mathrm{g} \mathrm{g}^{-1}\right.$ total carotenoids; D.F. Millie, pers. comm.). The estimated protein $(40 \%)$ and fat $(10 \%)$ content of these diets are similar to high-quality commercial feeds for tropical fishes.

\section{CAUDAL FIN REDUCTION AND ESTIMATION OF REGROWTH}

On day 0 of the experiment, each male was sedated with MS-222, standard length $\left(L_{\mathrm{S}}\right)$ was measured using digital callipers with a $0.01 \mathrm{~mm}$ readout, the left surface was photographed with an Olympus C2500-L digital camera, the posterior-most 25\% of the caudal fin (based on fin length) was removed with a sterilized scalpel (Nechiporuk \& Keating, 2002; Zodrow \& Tanguay, 2003), and the male was photographed again. To ensure that the point of $100 \%$ regrowth was not missed, each male was photographed again on days 4, 14 and 24 post-reduction. Between photographs, males were maintained in the experimental tanks and $25 \%$ water changes were performed weekly. The 24 day period was selected based on a previous study of fin regeneration in a poeciliid fish (Johnson \& Denton, 1977) and on pilot studies showing that most male guppies regenerated their caudal fins within this time.

\section{DATA ANALYSIS}

The digital photographs were used to measure caudal fin length (distance from the caudal peduncle to the posterior-most edge of the longest fin ray). Measurements were made with NIH Image 1.63 (National Institutes of Health, Bethesda, MD, U.S.A.). Absolute change in caudal fin length was calculated as: caudal fin length at day 24 minus caudal fin length immediately following reduction. The relative change in caudal fin length was calculated as: caudal fin length at day 24 minus caudal fin length immediately following reduction, divided by length of caudal fin removed. Two ANOVA models were constructed, with food level, carotenoid level and site resource availability as fixed-effects terms, to examine the regrowth of caudal fin length. These models also included a random-effects site nested within site resource availability term. The dependent variable was either absolute or relative change in caudal fin length. Initially, male age was incorporated as a covariate in both models. This term, however, was not statistically significant $(P>0.54$ for both models) and was excluded from the final models. Data were arcsine-square root transformed to meet parametric assumptions when necessary, and analyses were conducted using JMP 3.2.2 (SAS Institute, Inc., Cary, NC, U.S.A.), at a two-tailed alpha level of $0 \cdot 05$.

\section{RESULTS}

Males raised on the low food level were smaller $\left(L_{\mathrm{s}}\right)$ than males raised on the high food level (ANOVA, d.f. $=4$ and 174, $P<0 \cdot 001$ ). There was no difference in the length of caudal fin tissue removed from the low and high food males (mean \pm s.E. for both $1.24 \pm \theta \cdot 05 \mathrm{~mm}$; ANOVA, d.f. $=4$ and $174, P=+.94$ ). There was also no difference in the length of caudal fin tissue removed among carotenoid diet groups (ANOVA, d.f. $=2$ and 174, $P=\theta \cdot 21$ ) or among the four sites (ANOVA, d.f. $=\nless 2$ and $174, P=\theta \cdot 061$ ). None of the interaction terms was significant (all $P>0 \cdot 33$ ). 
There was no significant effect of carotenoid diet (ANOVA, absolute length: d.f. $=\&$ and 167, $P=\leftrightarrow \cdot 58$; relative length: d.f. $=\&$ and $119, P=\theta \cdot 81)$ or food level (ANOVA, absolute length: d.f. $=\$ 2$ and 167, $P=+0 \cdot 46$; relative length: d.f. $=2$ and $119, P=\theta \cdot 51$; [Fig. 1(a), (b)] on the change in caudal fin length. An analysis using $L_{\mathrm{S}}$-specific rates of fin regrowth, however, showed a marginally non-significant trend towards low food males regrowing fin tissue faster than high food males (mean \pm ss.E.: low food $0.25 \pm 0.01$ and high food $0.23 \pm 0.01 ; P=0.058)$. The four sites did not differ from each other in the regrowth of caudal fin tissue (ANOVA, absolute length: d.f. $=2$ and 167, $P=0 \cdot 12$; relative length: 2 and $119, P=40 \cdot 34)$, and males from the two high resource availability sites did not differ from their corresponding low resource availability sites (ANOVA, absolute length: d.f. $=4$ and 99, $P=0.99$; relative length: d.f. $=\{$ and 213, $P=+\theta \cdot 41)$. The difference between low and high resource availability sites, however, was influenced by food level: males from the low resource availability sites regenerated more fin tissue on the high food
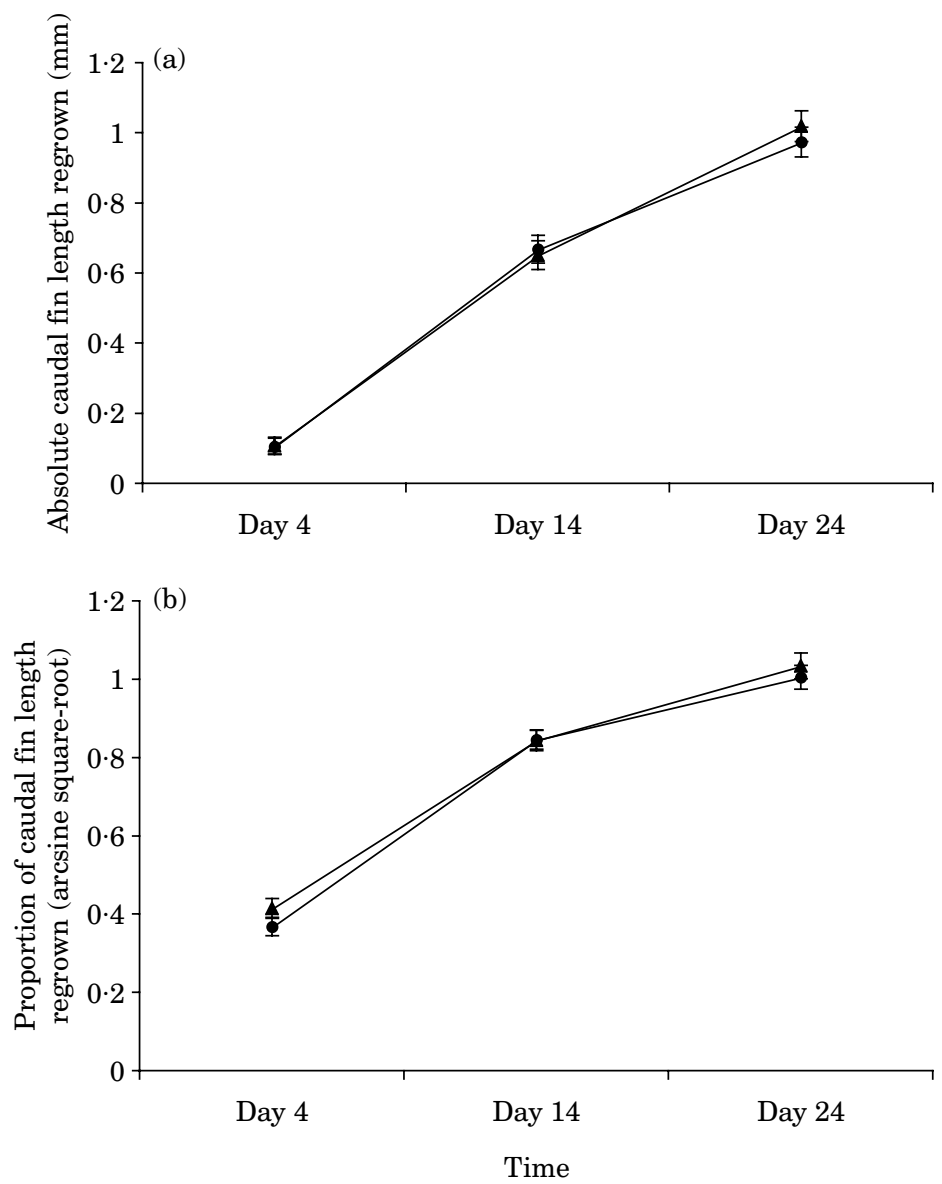

FIG. 1. Change over time in (a) absolute and (b) relative caudal fin length for males raised on the low food level $(\boldsymbol{\Delta})$ and the high food level $(\bullet)$. Values are least-squares means \pm ss.E. 
level than on the low food level, whereas males from the high resource availability sites regenerated more fin tissue on the low food level than on the high food level (ANOVA, food $\times$ site resource availability interaction, absolute tail length: d.f. $=4$ and 167, $P<0.001$; relative tail length: d.f. $=4$ and 119 , $P=\theta .004)$; [Fig. 2(a), (b)]. No other terms in the models were statistically significant (all $P>0 \cdot 07$ ).

\section{DISCUSSION}

There was no influence of carotenoid intake on the regrowth of experimentally-reduced caudal fin tissue in male guppies under laboratory rearing conditions. This contrasts with previous studies showing beneficial effects of carotenoids on immunity (Møller et al., 2000; Blount et al., 2003a; AlonsoAlvarez et al., 2004), but is consistent with previous findings of variable effects of carotenoids on different immune system parameters in male guppies. Carotenoid intake enhances the rejection response to foreign tissue (Grether et al., 2004), but the same carotenoid level decreases resistance to a naturallyoccurring external parasite (Kolluru et al., in press). These results emphasise that, even in species in which one aspect of the immune system is positively influenced by carotenoid intake, it should not be assumed that all aspects of immunity will be similarly affected (Blount et al., 2003b; Long \& Nanthakumar, 2004).

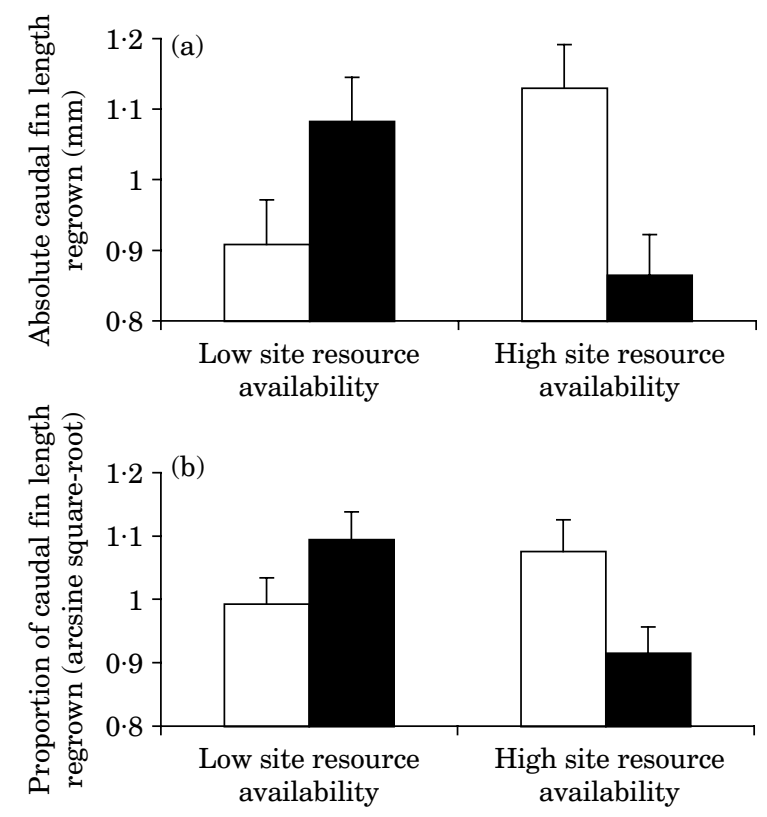

FIG. 2. Change in (a) absolute and (b) relative caudal fin length as a function of site resource availability for males raised on the low food level $(\square)$ and the high food level $(\boldsymbol{\square})$. Values are least-squares means \pm s.E. 
Carotenoids are either not necessary to successfully regrow fins while avoiding opportunistic infections to the injured tissue, or the experimental tanks did not contain sufficient levels of the bacteria and fungi responsible for opportunistic infections, such that the immune system was not activated to the extent that carotenoid mobilisation was required. The latter explanation, however, is contradicted by the occasional occurrence of such infections in the laboratory population. It is possible that the simultaneous inclusion of other stressors such as predators, which are not easily incorporated into a laboratory setting, would expose more substantial effects of carotenoid intake on fin regeneration.

In contrast to the effects of carotenoids, there were complex effects of food intake on fin regeneration. Because the low food males were smaller than the high food males, the lack of a main effect of food level on fin regeneration rates suggests that low food males may be able to regenerate fin tissue faster relative to their body size than high food males. This is supported by an analysis of sizespecific rates of fin regrowth, which showed a marginally non-significant trend towards low food males regrowing fin tissue faster than high food males. Caudal fin size influences swimming performance (Plaut, 2000) and also affects male guppy attractiveness to females, most likely via its influence on perceived body length (Bischoff et al., 1985; Endler \& Houde, 1995; Brooks \& Endler, 2001; Karino \& Matsunaga, 2002). Therefore, high food males, that have more resources at their disposal, were expected to devote relatively more energy to regenerating their fins than low food males. The results contradicted this prediction, perhaps because high food males allocated energy to other activities at the expense of fin regrowth. For example, males raised on the same high food level as used in this experiment engaged in aggressive interactions more frequently than males raised on the low food level (Kolluru \& Grether, 2005), and the high food males in the present study may have expended more energy on aggressive interactions than on fin regeneration. Alternatively, fin regeneration, which does not involve the growth of complex tissue such as muscle (Poss et al., 2003), may not be limited by energy intake.

The effects of food intake on fin regeneration were predicted to be more pronounced for males from the low resource sites, where the fish should have evolved a stronger plastic response to short-term changes in food availability (Kolluru \& Grether, 2005). The food level effect, however, was greater for males from the high resource availability sites. Interestingly, males appeared to be better at regenerating their fins when raised under the opposite food availability conditions from their sites of origin: males from low-resource sites regrew more fin tissue when raised on the high food level, and males from high-resource sites regrew more fin tissue when raised on the low food level. Because these males were raised in the laboratory, the differences among sites are either genetic or due to maternal effects. The interaction between food level and site resource level, and the greater effect of food intake on fin regrowth for males from high resource sites, may be explained by considering simultaneous behavioural tradeoffs made by the males. Males from the low resource sites show a less pronounced effect of food intake on aggressive behaviour (dominance interactions) than males from high resource sites (Kolluru \& Grether, 2005), though in both cases high food males are more aggressive. Thus, a plausible explanation for the interaction between food level and site resource availability is that at high 
resource sites, high food males put their extra resources into aggressive interactions in favour of fin regrowth, resulting in less fin regrowth compared to low food males, while at low resource sites, high food males do not make such a pronounced compromise between fin regeneration and aggressive behaviour, resulting in greater fin regrowth in high food males than in low food males. These considerations show the importance of taking multiple factors into account (i.e. behavioural as well as immunological) when studying resource allocation trade-offs.

Caudal fin removal was performed under approval by the UCLA Chancellor's Animal Research Committee and in accordance with the 'Guidelines for the treatment of animals in behavioural research and teaching' (Animal Behaviour 55 251-257). We thank Ocean Star International, Inc. for producing and donating the experimental diets, Roche Vitamins, Inc. for donating carotenoids, and D.F. Millie for analysing the carotenoid content of the diets. In Trinidad, we thank the Sinanan family for housing accommodations, the Ministry of Food Production, Marine Exploitation, Forestry, and the Environment for permits to collect guppies, and the Water and Sewage Authority for permission to work in the Crayfish drainage. This study was supported by National Science Foundation grants IBN-0001309 to GFG and IBN-0130893 to GFG and GRK.

\section{References}

Akimenko, M.-A., Marí-Beffa, M., Becerra, J. \& Géraudie, J. (2003). Old questions, new tools, and some answers to the mystery of fin regeneration. Developmental Dynamics 226, 190-201.

Alonso-Alvarez, C., Bertrand, S., Devevey, G., Gaillard, M., Prost, J., Faivre, B. \& Sorci, G. (2004). An experimental test of the dose-dependent effect of carotenoids and immune activation on sexual signals and antioxidant activity. The American Naturalist 164, 651-659.

Bakshi, M. G. \& Hiradhar, P. K. (1997). Effect of vitamin A on progress of fin regeneration in mudskipper Boleophthalmus dussumieri. Journal of Animal Morphology \& Physiology 44, 43-46.

Bischoff, R. J., Gould, J. L. \& Rubenstein, D. I. (1985). Tail size and female choice in the guppy (Poecilia reticulata). Behavioral Ecology and Sociobiology 17, 253-255.

Blount, J. D., Metcalfe, N. B., Birkhead, T. R. \& Surai, P. F. (2003a). Carotenoid modulation of immune function and sexual attractiveness in zebra finches. Science 300, 125-127.

Blount, J. D., Houston, D. C., Møller, A. P. \& Wright, J. (2003b). Do individual branches of immune defense correlate? A comparative case study of scavenging and non-scavenging birds. Oikos 102, 340-350.

Brooks, R. J. \& Endler, J. A. (2001). Direct and indirect sexual selection and quantitative genetics of male traits in guppies (Poecilia reticulata). Evolution 55, 1002-1015.

Endler, J. A. \& Houde, A. E. (1995). Geographic variation in female preferences for male traits in Poecilia reticulata. Evolution 49, 456-468.

Goodwin, T. W. (1984). The Biochemistry of the Carotenoids. London: Chapman \& Hall.

Grether, G. F. (2000). Carotenoid limitation and mate preference evolution: a test of the indicator hypothesis in guppies (Poecilia reticulata). Evolution 54, 1712-1724.

Grether, G. F., Hudon, J. \& Millie, D. F. (1999). Carotenoid limitation of sexual coloration along an environmental gradient in guppies. Proceedings of the Royal Society of London B 266, 1317-1322.

Grether, G. F., Millie, D. F., Bryant, M. J., Reznick, D. N. \& Mayea, W. (2001). Rain forest canopy cover, resource availability, and life history evolution in guppies. Ecology 82, 1546-1559. 
Grether, G. F., Kasahara, S., Kolluru, G. R. \& Cooper, E. L. (2004). Sex-specific effects of carotenoid intake on the immunological response to allografts in guppies (Poecilia reticulata). Proceedings of the Royal Society of London B 271, 45-49.

Hill, G. E. (1991). Plumage coloration is a sexually selected indicator of male quality. Nature 350, 337-339.

Houde, A. E. (1997). Sex, Colour, and Mate Choice in Guppies. Princeton, NJ: Princeton University Press.

Hõrak, P., Surai, P. F., Ots, I. \& Møller, A. P. (2004). Fat soluble antioxidants in broodrearing great tits Parus major: relations to health and appearance. Journal of Avian Biology 35, 63-70.

Johnson, D. A. \& Denton, T. E. (1977). Caudal fin regeneration in the mosquito fish, Gambusia affinis: an in vivo system for the study of ultraviolet radiation damage. Radiation Research 69, 241-247.

Karino, K. \& Matsunaga, J. (2002). Female mate preference is for male total length, not tail length in feral guppies. Behaviour 139, 1491-1508.

Karino, K. \& Shinjo, S. (2004). Female mate preference based on male orange spot patterns in the feral guppy Poecilia reticulata in Japan. Ichthyological Research 51, 316-320.

Kodric-Brown, A. (1989). Dietary carotenoids and male mating success in the guppy: an environmental component to female choice. Behavioral Ecology and Sociobiology 25, 393-401.

Kolluru, G. R. \& Grether, G. R. (2005). Resource availability and alternative mating tactics in guppies (Poecilia reticulata). Behavioral Ecology 16, 294-300.

Kolluru, G. R., Grether, G. F., South, S. H., Dunlop, E., Cardinali, A., Liu, L. \& Carapiet, A. (in press). The effects of carotenid and food availability on resistance to a naturally occuring parasite (Gyrodactylus turnbulli) in guppies (Poecilia reticulata). Biological Journal of the Linnean Society.

Latremouille, D. N. (2003). Fin erosion in aquaculture and natural environments. Reviews in Fisheries Science 11, 315-335.

Lellis, W. A. \& Barrows, F. T. (2000). Effect of dietary ingredient substitution on dorsal fin erosion of steelhead. North American Journal of Aquaculture 62, 135-138.

Long, K. Z. \& Nanthakumar, N. (2004). Energetic and nutritional regulation of the adaptive immune response and trade-offs in ecological immunology. American Journal of Human Biology 16, 499-507.

Lozano, G. A. (1994). Carotenoids, parasites, and sexual selection. Oikos 70, 309-311.

McGraw, K. J. \& Ardia, D. R. (2003). Carotenoids, immunocompetence, and the information content of sexual colours: an experimental test. American Naturalist 162, 704-712.

Møller, A. P., Biard, C., Blount, J. D., Houston, D. C., Ninni, P., Saino, N. \& Surai, P. F. (2000). Carotenoid-dependent signals: Indicators of foraging efficiency, immunocompetence or detoxification ability? Avian Poultry and Biology Review 11, 137-159.

Moutou, K. A., McCarthy, I. D. \& Houlihan, D. F. (1998). The effect of ration level and social rank on the development of fin damage in juvenile rainbow trout. Journal of Fish Biology 52, 756-770.

Munger, J. C. \& Karasov, W. H. (1989). Sublethal parasites and host energy budgets: tapeworm infection in white-footed mice. Ecology 70, 904-921.

Nechiporuk, A. \& Keating, M. T. (2002). A proliferation gradient between proximal and $m s x b$-expressing distal blastema directs zebrafish fin regeneration. Development 129, 2607-2617.

Olson, V. A. \& Owens, I. P. F. (1998). Costly sexual signals: are carotenoids rare, risky or required? Trends in Ecology and Evolution 13, 510-514.

Plaut, I. (2000). Effects of fin size on swimming performance, swimming behaviour and routine activity of zebrafish Danio rerio. The Journal of Experimental Biology 203, 813-820.

Poss, K. D., Keating, M. T. \& Nechiporuk, A. (2003). Tales of regeneration in zebrafish. Developmental Dynamics 226, 202-210. 
Santos-Ruiz, L., Santamarìa, J. A., Ruiz-Sànchez, J. \& Becerra, J. (2002). Cell proliferation during blastema formation in the regenerating teleost fin. Developmental Dynamics 223. 262-272.

Siva-Jothy, M. T. \& Thompson, J. J. W. (2002). Short-term nutrient deprivation affects immune function. Physiological Entomology 27, 206-212.

Snelson, F. F. (1989). Social and environmental control of life history traits in poeciliid fishes. In Ecology and Evolution of Livebearing Fishes (Poeciliidae) (Meffe, G. K. \& Snelson, F. F., eds), pp. 149-161. Englewood Cliffs, NJ: Prentice Hall.

Turnbull, J. F., Adams, C. E., Richards, R. H. \& Robertson, D. A. (1998). Attack site and resultant damage during aggressive encounters in Atlantic salmon (Salmo salar L.) parr. Aquaculture 159, 345-353.

Weis, P. \& Weis, J. S. (1976). Effects of heavy metals on fin regeneration in the killifish, Fundulus heteroclitus. Bulletin of Environmental Contamination and Toxicology 16, 197-202.

Zodrow, J. M. \& Tanguay, R. L. (2003). 2, 3, 7, 8-Tetrachlorodibenzo-p-dioxin inhibits zebrafish caudal fin regeneration. Toxicological Sciences 76, 151-161. 